\title{
Science and Technology Against Microbial Pathogens
}

Research, Development and Evaluation 
This page intentionally left blank 


\title{
Science and Technology Against Microbial Pathogens \\ Research, Development and Evaluation
}

\author{
Proceedings of the International Conference on \\ Antimicrobial Research (ICAR2010) \\ Valladolid, Spain \\ $3-5$ November 2010
}

\author{
editor \\ A. Mendez-Vilas
}

Formatex Research Center, Spain 


\section{Published by}

World Scientific Publishing Co. Pte. Ltd.

5 Toh Tuck Link, Singapore 596224

USA office: 27 Warren Street, Suite 401-402, Hackensack, NJ 07601

UK office: 57 Shelton Street, Covent Garden, London WC2H 9HE

\section{British Library Cataloguing-in-Publication Data}

A catalogue record for this book is available from the British Library.

\section{SCIENCE AND TECHNOLOGY AGAINST MICROBIAL PATHOGENS \\ Research, Development and Evaluation \\ Proceedings of the International Conference on Antimicrobial Research (ICAR2010)}

Copyright (C) 2011 by World Scientific Publishing Co. Pte. Ltd.

All rights reserved. This book, or parts thereof, may not be reproduced in any form or by any means, electronic or mechanical, including photocopying, recording or any information storage and retrieval system now known or to be invented, without written permission from the Publisher.

For photocopying of material in this volume, please pay a copying fee through the Copyright Clearance Center, Inc., 222 Rosewood Drive, Danvers, MA 01923, USA. In this case permission to photocopy is not required from the publisher.

ISBN-13 978-981-4354-85-1

ISBN-10 981-4354-85-6

Printed in Singapore. 


\section{Introduction}

This book contains a compilation of works which were presented at the International Conference on Antimicrobial Research (ICAR2010), which took place in Valladolid (Spain), during November $3^{\text {rd }}-5^{\text {th }} 2010$ (http://www.formatex.org/icar2010). This inaugural edition was attended by more than 500 delegates from about 60 countries.

Plenary Lectures were given by Paul Williams, from the Centre for Biomolecular Sciences, Nottingham University (UK), who talked about "Quorum sensing as an antibacterial target"; Stephen Bentley, from the Wellcome Trust Sanger Institute, Cambridge (UK), with a speech entitled "Viewing evolution and global spread of drug resistant bacterial pathogens through whole genome sequencing"; and Thierry Jouenne, from the Facility of the European Institute for Peptide Research, University of Rouen (France), who delivered the speech "The Biofilm proteome: the holy grail”.

This conference series will provide a new forum in Europe for the presentation, exchange and dissemination of information and experiences on anti-microbe strategies (against bacteria, fungi or protozoans), in biotic or abiotic environments, in planktonic or adhered states, in biologically specific or unspecific ways, in vitro or in vivo, in a general context marked by the threat posed by the increasing antimicrobial resistance of pathogenic microorganisms. "Anti" is here taken in a wide sense as "against cell cycle, adhesion, or communication", when harmful for human health, industry or economy (infectious diseases, chemotherapy, food, biomedicine, agriculture, livestock, biotechnology, water systems...). It will include topics on antimicrobial resistance, (early) microbial and resistance detection, enhancement of innate defences against pathogens, as well as methods \& techniques.

The topics discussed at the conference were:

\section{Antimicrobial chemistry (experimental and computational). Analytical detection of antibiotics in complex samples.}

Synthesis and screening of novel chemical compounds for antimicrobial action. Natural, synthetic and semisynthetic antibiotics. Analogs. Structural determination. In-silico/ab-initio/de-novo antimicrobials discovery. New targets for antimicrobials. Rational design of antimicrobials. Bioinformatics and comparative genomics for the identification of antimicrobial targets...

\section{Antimicrobial natural products.}

Antimicrobial substances from terrestrial and marine organisms. Antimicrobial peptides. Antimicrobial enzymes. Essential oils. Bioactive phytochemicals. Plant/Herbal extracts. Purification. Structural determination...

\section{Antimicrobials mechanisms of action.}

Methods and Techniques.

Antimicrobial resistance. Superbugs. Multi-resistant strains. Emerging and re-emerging pathogens.

Microbial resistance to antibiotics and biocides. Molecular mechanisms. Resistance genes. Prevention of resistance. Surveillance \& statistics. Genetics and Proteomics. Emerging and re-emerging bacteria and fungi in humans, animals, and plants. Methicillin-resistant Staphylococcus aureus (MRSA), Vancomycin Intermediate/Resistant Staphylococcus aureus (VISA/VRSA), Clostridium difficile, Mycobacterium tuberculosis, Vancomycin-resistant enterococcus (VRE), Cryptosporidium, Plasmodium parasite, Plasmodium falciparum, Leishmania species, Klebsiella pneumoniae, Streptococcus pneumoniae, Acinetobacter baumannii, Cryptococcus, Escherichia coli O157:H7, Helicobacter spp., Enterobacter sakazakii, Serratia spp., Fluoroquinolone-Resistant Pseudomonas aeruginosa (FQRP)...

\section{Antimicrobial microbes.}

Microbial-derived toxins. Bacteriocins (colicins, microcins, lantibiotics...). Archaeocins. Biocontrol approach to microbial invasions (probiotics, lactic acid bacteria...). Biosynthesis of antibiotics. Genetic and metabolic engineering. Gene regulation...

\section{Antimicrobial viruses.}

Bacteriophages. Phage therapy and biocontrol in humans, animals (agriculture-farm animals, aquaculture), plants, food industry... Materials functionalization with bacteriophages. Using bacteriophages for microbiological detection... 
Antimicrobial materials science and surface chemistry. Biofilms.

Antimicrobial, anti-adhesive surfaces \& coatings. Microbial adhesion to surfaces. Biofouling. Biofilm formation, control and eradication. Novel characterization techniques. Physical and chemical (inorganic (e.g. silver, copper compounds) and organic) surface modification. Cationic surfaces. Functionalization strategies for polymers, metals, metal oxides, ceramics. Drug-eluting concepts. Biofilms susceptibility to antimicrobials. Antibiotic resistance of microorganisms in biofilms. Genomics and Proteomics...

\section{Antimicrobials in consumer products.}

Textiles (hygienic clothing, activewear, medical textiles...), paper industry, active packaging (food industry...), public buildings (hospitals, schools, restaurants, day care centers, nursing homes...). Safety and toxicological aspects...

\section{Antimicrobial physics.}

Exploitation of physical properties for killing/inactivating microbes: surface tension (nano-emulsions), radiation, ultrasounds, temperature, specific properties of nano-materials (nano-particles, nano-tubes/wires, nano-crystals, nano-grained materials...). Resistance to physical agents...

\section{Non-antibiotic biocides. Hygiene and Sterilizing.}

Disinfectants, antiseptics, preservatives... Mechanism of action. Resistance to non-antibiotic biocides. Combination of physical and chemical treatments. Hygiene and Sterilizing. Sanitizers. Regulatory issues. Good practices...

\section{Techniques and Methods.}

Susceptibility Testing. Rapid microbial and resistance detection. Detection of antibiotics in environmental samples. Microscopy, microanalysis \& spectroscopy, single-cell studies, high-throughout studies, nanomechanical studies, microfluidics, lab-on-a-chip concepts, miniaturized science, analysis of microbial surfaces, heterogeneity, statistics. Interaction of antimicrobial drugs with model membranes. Analytical techniques...

\section{The Intelligent war.}

Interfering microbe-microbe communication (quorum sensing) as antimicrobial strategy.

Strengthening of innate immune system as antimicrobial strategy.

Immunotherapy, immunomodulating agents, cytokines (interleukins, colony-stimulating factors, interferons...), hormones... Novel vaccines for preventing or treating disease...

\section{Antimicrobials evaluation. Pre-clinical and clinical trials.}

Public awareness, learning $\&$ teaching, influence on policy-makers. Regional regulatory frameworks and experiences on antimicrobials.

\section{Organizing Committee:}

A. Méndez-Vilas, Formatex Research Center, Badajoz, Spain (General Coordinator)

J. A. Mesa González, Formatex Research Center, Badajoz, Spain (Secretariat)

A. Solano Martín, Formatex Research Center, Badajoz, Spain (Secretariat)

J. Mesa González, Formatex Research Center, Badajoz, Spain

J. Díaz Álvarez, Department of Organic and Inorganic Chemistry, University of Extremadura, Badajoz, Spain

A. Agudo Rodríguez, Formatex Research Center, Badajoz, Spain

\section{Scientific Advisory Committee:}

David Newman, Natural Products Branch and Pharmaceutical Resources Branch, Developmental Therapeutics Program, Division of Cancer Treatment and Diagnosis, National Cancer Institute, Maryland, USA

Catherine Stanton, Teagasc, Moorepark Food Research Centre, Fermoy, Co. Cork, Ireland 
David Wareham, Queen Mary University London, Centre for Immunology and Infectious Disease, Blizard Institute of Cell and Molecular Science, Barts \& The London School of Medicine and Dentistry, London, UK

Debora B Barbosa, Department of Dental Materials and Prosthodontics, Araçatuba Dental School, São Paulo State University (UNESP), Araçatuba, SP, Brazil

Karl Lohner, Institute of Biophysics and Nanosystems Research, Austrian Academy of Sciences, Graz, Austria

Gill Diamond, Department of Oral Biology, UMDNJ-New Jersey Dental School, Newark, NJ, USA

Francieso Xavier Malcata, Centre of Biotechnology and Fine Chemicals, School of Biotechnology, Portuguese Catholic University, Porto, Portugal

Manuel V. Simões, LEPAE, Department of Chemical Engineering, Faculty of Engineering, University of Porto, Porto, Portugal

Sun Chul Kang, Department of Biotechnology, College of Engineering, Daegu University, Kyoungsan, Kyoungbook, Republic of Korea

Robert A. Bonomo, Department of Medicine, Pharmacology, Molecular Biology and Microbiology, Case Western Reserve University School of Medicine, Cleveland, Ohio, USA, and Research Service, Louis Stokes Cleveland Department of Veterans Affairs Medical Center, Cleveland, Ohio, USA

Mahendra Rai, Department of Biotechnology, Sant Gadge Baba Amravati University, Amravati, Maharashtra, India

Pascal M. Dohmen, Department of Cardiovascular Surgery, Charité Hospital, Medical University Berlin, Berlin, Germany

Francois Niyonsaba, Atopy (Allergy) Research Center, Juntendo University School of Medicine, Hongo, Bunkyo-ku, Tokyo, Japan

Roland Pieters, Department of Medicinal Chemistry and Chemical Biology, Utrecht Institute for Pharmaceutical Sciences, Utrecht University, Utrecht, The Netherlands

Geraint Rogers, Molecular Microbiology Research Laboratory, Pharmaceutical Science Division, FranklinWilkins Building, King's College London, London, UK

Octávio Luiz Franco, Department of Biology, Federal University of Juiz de Fora, Juiz de Fora, MG, Brazil

Fiona Regan, National Centre for Sensor Research, School of Chemical Sciences, Dublin City University, Glasnevin, Dublin, Ireland

Miguel Castanho, Centre of Chemistry \& Biochemistry, Faculty of Sciences, University of Lisbon, Lisbon, Portugal

Pilar García Suárez, Department of Technology and Biotechnology of Dairy Products, Dairy Products Institute of Asturias (IPLA-CSIC), Asturias, Spain

Valerie Edwards-Jones, Manchester Metropolitan University, Manchester, UK

Jürgen Reichling, Institute of Pharmacy and Molecular Biotechnology, Department of Biology, University of Heidelberg, Heidelberg, Germany

Neil Marsh, Department of Chemistry, University of Michigan, Ann Arbor, MI, USA.

Paul M. Tulkens, Cellular and Molecular Pharmacology Unit, Catholic University of Louvain, Brussels, Belgium

Kevin Laupland, O'Brien Centre for the Bachelor of Health Sciences Program, Health Sciences Centre, Faculty of Medicine, University of Calgary, Alberta, Canada

Martti Vaara, Northern Antibiotics Ltd, Helsinki, Finland.

Paavo Kinnunen, Helsinki Biophysics and Biomembrane Group, Medical Biochemistry, Institute of Biomedicine, University of Helsinki, Finland

Ray Dawson, DSTO (Defense Science \& Technology Organisation), Melbourne, Australia

Tim Maisch, Antimicrobial PDT, Clinic and Polyclinic for Dermatology, Regensburg University Hospital, Germany

Angel Concheiro, Department of Pharmacy and Pharmaceutical Technology, University of Santiago de Compostela, Santiago de Compostela, Spain

Tatsushi Mogi, Department of Biomedical Chemistry, Graduate School of Medicine, The University of Tokyo, Tokyo, Japan

Juana Fernández-López, Agrofood Technology Department, Miguel Hernández University, Alicante, Spain

Quintín Rascón-Cruz, Faculty of Chemical Sciences, Autonomous University of Chihuahua, Chihuahua, Mexico

Xiaoqiang Wang, Plant Biology Division, Samuel Roberts Noble Foundation, Ardmore, OK, USA

Maria Luisa Mangoni, Istituto Pasteur-Fondazione Cenci Bolognetti, Department of Biochemical Science and Unit of Advanced Molecular Diagnostic, II Faculty of Medicine and Surgery, Rome, Italy

PJ Cullen, School of Food Science and Environmental Health, Dublin Institute of Technology, Dublin, Ireland 
Enrique Querol, Biotechnology and Biomedicine Institute, Autonomous University of Barcelona, Barcelona, Spain

Shunmugaperumal Tamilvanan, Department of Pharmaceutical Sciences, University of Antwerp, Antwerp, Belgium

Arvind Bansal, Department of Computer Science, Kent State University, Kent, Ohio, USA

Maria do Carmo Bastos, Institute of Microbiology Prof. Paulo de Góes, UFRJ, Rio de Janeiro, Brazil

Axel Dalhoff, Institute for Infection Medicine, University Hospital Schleswig-Holstein, Kiel, Germany

Kevin J Saliba, Medical School \& Research School of Biology, College of Medicine, Biology and Environment, The Australian National University, Canberra, Australia

Richard W. Scott, PolyMedix, Inc., Radnor, PA, USA

Amparo Estepa, IBMC, Miguel Hernández University, Elche, Spain

Elrefaie Sobhy Kenawy, Polymer Research Group, Chemistry Department, Faculty of Science, Tanta University, Tanta, Egypt

Isidra Recio, Institute of Industrial Fermentation (CSIC), Madrid, Spain

Emilio Montesinos, Institute of Food and Agricultural Technology, University of Girona, Girona, Spain

Jagat R. Kanwar, Institute for Technology \& Research Innovation (ITRI), Deakin University, Geelong, Australia

Amlan K. Patra, West Bengal University of Animal \& Fishery Sciences, Kolkata, India

Ahmed Yousef, The Ohio State University, USA

Hao Zhang, School of Food Science and Technology, Jiangnan University, China

Gregory N. Tew, Department of Polymer Science \& Engineering, University of Massachusetts, Amherst, USA

Venue

Congress Center of Valladolid (Feria Valladolid), Valladolid, Spain.

\section{centrodecongresos deValladolid}

\section{Media Sponsors}
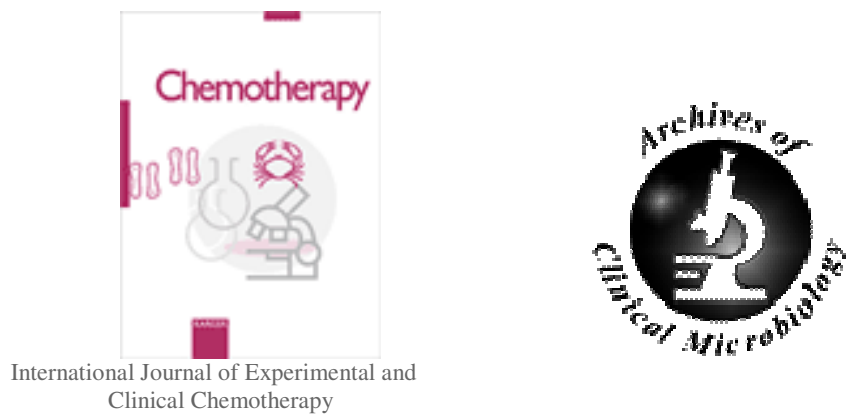

\section{DANISCO}

First you add knowledge... 


\section{Contents}

Introduction

\section{Antimicrobial Peptides}

A new class of Scots pine antimicrobial proteins, which act by binding $\beta$-glucan

Sanjeewani Sooriyaarachchi, Adrian Suárez Covarrubias, Wimal Ubhayasekera, Frederick O. Asiegbu and Sherry L. Mowbray.....

Antimicrobial aza- $\beta^{3}$-peptides: Structure-activity relationship?

B. Legrand, M. Laurencin, C. Zatylny-Gaudin, J. Henry, A. Bondon and M. Baudy Floc'h

Differential antimicrobial activities of Human Beta-Defensins against Methicillin Resistant (MRSA) and Methicillin sensitive (MSSA) Staphylococcus aureus

N. D. S. Herathge, J. T. George and D. A. Rowley

Isolation of antimicrobial peptides from New Zealand spinach Tetragonia tetragonioides

T. Neubauerová, M. Macková, T. Macek, M. Šanda, M. Králová, I. Doležílková and P. N.

Holmsgaard.

Lysostaphin: molecular changes that preserve staphylolytic activity

S. Becker, J. Foster-Frey, A. Powell, H. Mohammadi, D. E. Kerr and D. M. Donovan.

Purification and characterization of antimicrobial peptides from fleshfly larvae haemolymph

T. Neubauerová, M. Macková, T. Macek, M. Šanda and Z. Vobůrka

Structural and functional diversity of natural antimicrobial oligopeptides

Aexander A. Zamyatnin

The role of Gram-negative envelope LPS on the bactericidal properties of proteins and peptides: the case of eosinophil cationic protein

D. Pulido, M. Torrent, M. V. Nogués and E. Boix

\section{Non-antibiotics Biocides}

Evaluation of biocidal activity of Evolyse, a disinfectant based on hydrogen peroxide and silver nitrate M. Barbara Pisano, V. Altana, M. Elisabetta Fadda, L. Mura, M. Deplano and S. Cosentino

Increased resistance to detergent in Enterococcus faecalis

Jacqueline Keyhani and Ezzatollah Keyhani

Legionella pneumophila isolation rate in a Spanish hospital pre- and post-installation of an electrochemical activation system for potable water disinfection

Jose-Maria Rivera, Juan-Jose Granizo, Jose-Maria Aguiar, Ana Vos-Arenilla, Maria-Jose Giménez and Lorenzo Aguilar

\section{Antimicrobial Evaluation: Clinical and Pre-clinical Trials}

Adherence to ART and its associated factors among HIV Aids Patients in Addis Ababa

Ezra Muluneh. 
Effectiveness and safety of miconazole with hydrocortisone (Daktacort) feminine care cream in the treatment of vulvar candidiasis

J. Perez-Peralta and G. Balaccua

\section{Natural Products: Terrestrial and Marine Organisms}

Analysis of the 2-Phenylethyl isothiocyanate present in Brassica leaves and their potential application as antimicrobial agent against bacteria strains isolated from Human and Pig gastrointestinal tracts

A. Aires, C. Dias, R. N. Bennett, E. A. S. Rosa and M. J. Saavedra.

Antimicrobial effect of carvacrol on Escherichia coli K12 growth at different temperatures

C.M. Belda-Galbis, A. Martínez and D. Rodrigo.....

Bacteriostatic effect of cocoa powder rich in polyphenols to control Cronobacter sakazakii proliferation on infant milk formula

M. C. Pina-Pérez, D. Rodrigo and A. Martínez-López

Curcumin: a natural antibiofilm agent

Maya Moshe, Jonathan Lellouche and Ehud Banin.....

Evaluation of in vitro and in vivo antibacterial and antifungal activity of "Camelyn M"

Benedikte Maglakelidze, Guguli Abashidze, Inga Dadeshidze, Vakxtang Mshvildadze, Andre

Pichete, Vincent Perreten, Shota Tsanava, Nata Shubladze and Koba Gurielidze

In vitro antifungal activity of several essential oils from aromatic plants of Aragón (NE, Spain)

S. Lorán, O. Segman, C. Rota, P. Conchello and A. Herrera

Influence of some natural compounds on freshwater microfoulants

O. A. Cuzman, C. Faraloni, T. Turchetti, M. Camaiti and P. Tiano

Natural antimicrobial agents against the microbiota associated with insoles

N. Cuesta Garrote, M. M. Sánchez Navarro, F. Arán Aís and C. Orgilés Barceló.

Plant essential oils and their components for the control of phytopathogen and mycotoxigenic fungi in crops

C. Morcia and V. Terzi.

Possibility of using Rosmarinus officinalis, Myrtus communis and Origanum sp.'s essential oil as fungicide in pickling and tanning processes

Eser Eke Bayramoglu.

Screening of aqueous methanol plant extracts for their antibacterial activity

Kashif Nauman and Muhammad Arshad

\section{Antimicrobial Surfaces. Biofilms. Quorum Sensing. Consumer Products.}

Antimicrobial active packaging films based on sorbic acid

C. Hauser, J. Wunderlich and G. Ziegleder

Bacteriophages actions on Salmonella Enteritidis biofilm

A. A. Ferreira, R. C. S. Mendonça, H. M. Hungaro, M. M. Carvalho and J. A. M. Pereira. 
Biocompatibility and antibacterial property of cold sprayed $\mathrm{ZnO} /$ Titanium composite coating Noppakun Sanpo, Chen Hailan, Kelvin Loke, Koh Pak Keng, Philip Cheang, C. C. Berndt and K. A. Khor

Effect of penicillins on the acidification of yogurt made from ewe's milk during the storage

M. I. Berruga, M. C. Beltrán, B. Novés, A. Molina and M. P. Molina

Exploring thermostable quorum quenching lactonases to counteract bacterial infections in cystic fibrosis

L. Mandrich, E. Porzio, L. Merone, F. Febbraio, R. Nucci and G. Manco.

Furanones and Thiophenones in Control of Staphylococcus epidermidis Biofilm Infections?

J. Lönn-Stensrud, T. Benneche and A. A. Scheie.

Innovative High Surface Area CuO Pretreated Cotton Effective in Bacterial Inactivation under Visible Light

A. Torres, C. Ruales, C. Pulgarin, A. Aimable, P. Bowen, V. Sarria and J. Kiwi.

Is synergy of antimicrobials the effective way of management of resistance among cosmetically significant skin microflora?

B. K. Mohanty, S. Gokul Shankar, M. S. Ranjith and M. Prabhamanju

Microencapsulation of Melaleuca alternifolia (tea tree) oil as biocide for footwear applications

M. M. Sánchez-Navarro, N. Cuesta-Garrote, F. Arán-Aís and C. Orgilés-Barceló .....

Plasma polymerisation and retention of antibacterial properties of terpinen-4-ol

Kateryna Bazaka, Mohan V. Jacob, Russell J. Crawford and Elena P. Ivanova.

Preparation of silver or zinc loaded nanocapsules with core-shell architecture and their application as metal-ion release agents in plastics leading to antibacterial and fungicidal surface properties

M. Gladitz, S. Reinemann, J. Bauer and H. J. Radusch

Structure-reactivity relations for DC-magnetron sputtered Cu-layers during E. coli inactivation in the dark and under light

C. Castro, R. Sanjines, C. Pulgarin, P. Osorio, S. A. Giraldo and J. Kiwi.

Study of submerged and biofilm fermentation of Bacillus subtilis using fish protein for production of lipopeptide antibiotic iturin A

Umme Salma Zohora, Abdul Wahab Khan, Masahiro Okanami, Takashi Ano and Mohammad Shahedur Rahman

The influence of DC air plasma and cellulase enzyme on the antimicrobial activity of Azadirachtin (neem leaf extract) treated cotton fabric

E. Nithya, S. Jayakumar, K. Vaideki and R. Rajendran

Urolithins, metabolites produced by human colonic microflora, act as Quorum Sensing inhibitors of Yersinia enterocolitica affecting its gene expression

J. A. Giménez, P. Truchado, M. Larrosa, J. C. Espín, F. Tomás-Barberán, M. T. García-Conesa and A. Allende

Use of lactic acid bacteria biofilms as biocontrol agents

Emel Ünal, Selin Kalkan and Zerrin Erginkaya 


\section{Methods and Techniques. Mechanisms of Action. Physics.}

A new approach for detection of bacterial contamination in cooling lubricants

D. Oberschmidt, A. Spielvogel, C. Hein, J. E. Langbein, D. Lorenz, U. Stahl and E. Uhlmann.

Development of a liquid-medium assay for screening antimicrobial natural products against marine bacteria

M. Geiger, J. Dupont, O. Grovel, Y. F. Pouchus and P. Hess

Experimental planning can help to optimize the selective photoinactivation of microorganisms

J. R. Perussi, P. L. Fernandes, C. Bernal and H. Imasato.

Fungal evaluation on oolong tea irradiated with different water activities

G. B. Fanaro, R. C. Duarte, F. T. Rodrigues, B. Corrêa and A. L. C. H. Villavicencio

Gamma radiation effects on bacteria and fungi in coffee (Coffea arabica L.)

F. T. Rodrigues, R. C. Duarte, G. B. Fanaro and A. L. C. H. Villavicencio

Irradiation effect on antifungal potential of clove essential oil

R. C. Duarte, G. B. Fanaro, F. T. Rodrigues and A. L. C. H. Villavicencio

Microarray for rapid detection of microbial resistance genotypes

Tomasz A. Leski, Gary J. Vora, Brian Barrows, Guillermo Pimentel and Chris R. Taitt.

Photosensitization as human and environmentally friendly antimicrobial tool

Zivile Luksiené

Rapid diagnosis of neonatal bacteremia using polymerase chain reaction

Amany El-Sharif and Raghdaa Ali

Shelf life extension of semi-dried fish Nile Tilapia (Oreochromis niloticus) by ultraviolet and infrared irradiations

Narumol Matan

Study on the effect of RF plasma pretreatment on the antimicrobial efficacy of neem leaf extract processed cotton fabric

K. Vaideki, S. Jayakumar, E. Nithya and R. Rajendran ....

\section{Resistance and Susceptibility}

A 3-year review on the profile of multidrug-resistant Gram-negative in a tertiary teaching hospital in Malaysia

H. Habsah, Z. Z. Deris, M. Zeehaida, A. R. Zaidah, H. Siti Asma'and I. Nabilah.

Antimicrobial susceptibility in clinical isolates of Staphylococcus aureus harbouring of mecA and $l u k$ FS-PV genes in Northern Portugal

N. Silva, C. Prudêncio, C. Tomaz and R. Fernandes

Antimicrobial susceptibility profile and effect of stem bark extracts of Curtisia dentata on multi-drug resistant verotoxic Escherichia coli and Acinetobacter spp. isolates obtained from water and wastewater samples

Hamuel James Doughari, Patrick Alois Ndakidemi, Izanne Susan Human and Spinney Benade

Antimicrobial utilization in Intensive care units of a private tertiary care hospital

Pramil Tiwari, Vani Yadav and Shilpi Singh ...... 
Bacterial clearance from blood in mice infected by S. pneumoniae (penicillin MIC $=16 \mu \mathrm{g} / \mathrm{ml}$ ) presenting specific IgG (non-protective levels) and treated with sub-therapeutic regimens of cefditoren (a highly bound cephalosporin)

Fabio Cafini, Jose Yuste, Maria-Jose Giménez, David Sevillano, Lorenzo Aguilar, Luis Alou, Martha Torrico, Natalia González, Ernesto García, Jose Prieto and Pilar Coronel .

Characterisation of methicillin resistant Staphylococcus aureus isolates from hospitalised patients

Vladimir Kmet, Daniela Ohlasova and Milan Niks.

Characterization of methicillin-resistant coagulase-negative Staphylococci Isolates from blood cultures in a Brazilian University Hospital

Valéria Cataneli Pereira and Maria de Lourdes Ribeiro de Souza da Cunha.....

Control of bacterial contamination in boar semen doses

J. M. Morrell and Margareta Wallgren

Diffusion of extended-spectrum $\beta$-lactamase producing Enterobacter cloacae in a kidney transplantation unit

S. Hammami, I. Boutiba-Ben Boubaker, A. Kamoun, R. Ghozzi, M. Saidani, A. Slim and S. Ben Redjeb.

Effect of antifungal agents on non-Candida albicans Candida species enzymatic activity

M. Negri, T. Lorenço, S. Silva, M. Henriques, J. Azeredo and R.Oliveira.

Effect of chitosan, nisin and storage time on the growth of Listeria innocua and Shewanella putrefaciens in fish homogenates

L.I. Schelegueda, M.F. Gliemmo and C.A. Campos.

ESBL-producing Enterobacteriaceae in the northern portugal - antimicrobial susceptibility and molecular epidemiology

R. Fernandes and C. Prudêncio

Observations on the antimicrobial susceptibility of Staphylococcus pseudintermedius following the introduction of cefovecin for clinical use in Europe

Y. Chaudhry, A. Robinson and K. S. Godinho

Oxacillin resistance among Staphylococcus aureus isolated from peritoneal dialysis related peritonitis

C. H. Camargo, T. M. C. Moraes, M. L. R. S. Cunha, J. Caramori, A. L. Mondelli, A. C. Montelli and P. Barretti.

Resistance detection and susceptibility profile in Staphylococcus spp. isolated from patients with Urinary Tract Infection (UTI)

Adriano Martison Ferreira, Mariana Fávero Bonesso, Alessandro Lia Mondelli and Maria de Lourdes Ribeiro de Souza da Cunha.....

Resistance distribution profile of MBL, ESBL and multidrug resistant Gram negatives isolated at a tertiary care hospital in India

K. H. Bhutada and V. R. Shende.

Study on selection and transfer of antimicrobial resistant Escherichia coli from broiler breeders to their progeny

G. Manfreda, F. Pasquali, A. Lucchi, A. De Cesare, D. Giovanardi, M. Stonfer and A. Franchini

Survey of Fusarium species infecting potato and their resistance to fungicides used in Canada

K. Lugosch, R. D. Peters, T. Barasubiye and K. Drake

Vancomycin Resistant Enterococci (VRE) in equine-faecal samples

Mohamed O. Ahmed, Peter D. Clegg, Nicola J. Williams, Keith E. Baptiste and Malcolm Bennet 


\section{Chemistry}

Antimicrobial cyclic pseudopeptides including Aza- $\beta^{3}$-amino acids

M. Laurencin, B. Legrand, L. Mouret, A. Bondon, Y. Fleury and M. Baudy Floc'h

Effect of paracetamol on the pharmacokinetics of cephalexin in dogs

N. A. Afifi, M. Atef, K. Abo-El-Sooud and N. El-Mokadem.

Importance of the $\mathrm{C} 9$ absolute configuration for the antifungal activity of natural and semisynthetic sesquiterpenes

M. Derita, M. Di Liberto and S. Zacchino

Specificity determinants dramatically reduce hemolytic activity in amphipathic $\alpha$-helical antimicrobial peptides: antimicrobial activity against Gram-negative pathogens, Acinetobacter baumannii and Pseudomonas aeruginosa

Ziqing Jiang, Adriana I. Vasil, Lajos Gera, Michael L. Vasil and Robert S. Hodges.

Studies to find a better high level disinfectant for heat-sensitive endoscopes

Norman Miner, Valerie Harris, Towanda Ebron and Natalie Lukomski

Towards the rational design of antimicrobial peptides: Recent developments in computational tools

M. Torrent, D. Andreu, M. V. Nogués and E. Boix

\section{Antimicrobial Microbes and Viruses. Biosynthesis of Antibiotics}

Antimicrobial properties of Lactobacillus plantarum Tensia (DSM 21380) and Inducia (DSM 21379)

M. Rätsep, P. Hütt, R. Avi, M. Utt and E. Songisepp

Cell growth control by tRNase ribotoxins from bacteria and yeast

Eyemen Kheir, Christian Bär, Daniel Jablonowski and Raffael Schaffrath.

Comparison of anti-listerial effect spectrum of bacteriocins

Selin Kalkan, Emel Ünal, Zerrin Erginkaya

Isolation and screening of novel antibiotic producing Streptomyces from southwest Turkey soils

A. Ugur and O. Ceylan.

Production and characterization of enterocin from Enterococcus faecium IJ-06 and IJ-21 isolated from indigenous dairy products

Imran Javed and Safia Ahmed.

Structural model for a holin-like protein Tmp3 exhibiting broad spectrum antibacterial activity

Thangamani Rajesh and Paramasamy Gunasekaran.

The hospital environment as a source of new antimicrobial substances: antimicrobial activity of Bacillus amyloliquefaciens strain HNA3 isolated in a surgery room

M.Guida, R. A. Nastro, M. Inglese, M. Trifuoggi, S. Scherillo, R. Gesuele, V. Di Onofrio and G. Liguori...

The Inhibitor activity of Lactobacillus rhamnosus against rope-forming Bacillus strains

Selçuk Arslan, Zerrin Erginkaya, Emel Ünal..

Uncovering the mechanism of resistance against type III bacteriocin, enterolysin A

L. Maliničová, M. Piknová, P. Pristaš and P. Javorský. 